\title{
MUCORMICOSE ESPONTANEA EM PULMÃO DE COELHO
}

\author{
Antônio Carneiro Lopes *
}

\begin{abstract}
O autor descreve em coelho de raça Chinchila, com aproximadamente um ano de idade, apresentando nódulos miliares nos pulmóes, um caso de mucormicose pulmonar. O autor, utilizando PAS, comprovou a presença de micélio não septado e ramificado que se localizava de preferência na luz de pequenos vasos pulmonares, ao redor dos quais havia reaçấo inflamatória do parênquima pulmonar.
\end{abstract}

\section{INTRODUÇÃO}

A infecção por fungos de gênero $M u c o r$, pode acometer os animais e o homem; há indícios de que êstes cogumelos vivam no ar e sua patogenicidade só é revelada em determinadas condições. Na espécie humana a primeira descrição a respeito foi feita por Paltulf em 1885 (6), que encontrou o cogumelo em abcesso de pulmão, cerebelo, cérebro, faringe e íleo. Zapater (9) cita-o como fungo de propriedade alergênica e responsabiliza-o como causador de rinites, bronquites e asma alérgica na espécie humana. Mcquown e Moss em 1953 (5), admitem o Mucor sp. como produtor de otomicoses, infecção primária de pulmão e possivelmente infecção cerebelar.

$\mathrm{Na}$ espécie bovina esta micose tem sido responsabilizada como uma das causas esporádicas de abôrto. Smith, em 1920 (8), isolou de placenta, pulmão e intestino de feto bovino o Mucor rhizopodiformes e reproduziu a doença em coelho, por inoculação intravenosa de esporos. Bauer e col. (2), provocando em coelhos o diabete aloxânico, e inoculando nos mesmos e em coelhos normais, esporos do gênero Rhizopus e Absidia, por via intranasal para reproduzir a mucormicose cerebral, registraram os seguintes resultados:

a) inoculação com esporos de Rhizopus orizde, em 9 coelhos diabéticos e 9 normais, observaram que entre os coelhos diabéticos, 7, apresentaram lesões nasais; 3, meningo-encefalite; 3 broncopneumonia e 2 nefrite; entre os normais apenas 1 apresentou lesões nasais.

b) inoculaçōes com esporos de Rhizopus arrhizus, em 3 coelhos diabéticos e 2 normais, verificaram entre os diabéticos, 3 com lesões nasais e 2 com meningo-encefalite, $1 \mathrm{com}$ broncopneumonia e $1 \mathrm{com}$ nefrite; nos coelhos normais apenas $1 \mathrm{com}$ lesões nasais.

c) inoculações com esporos de Absidia ramosa, em 3 coelhos diabéticos e 3 coelhos normais, constataram nos coelhos diabéticos, $3 \mathrm{com}$ lesões nasais, $1 \mathrm{com}$ meningo-encefalite, 3 com broncopneumonia; os ccelhos normais não apresentaram alterações.

d) inoculações com esporos Absidia corymbifera, em 3 coelhos diabéticos e $\mathbf{3}$ normais, constataram entre os diabéticos, I com lesāo renal, 1 com broncopneumonia; nos coelhos normais apenas 1 apresentou lesões nasais.

(1) Médico_Veterinário do Instituto Estadual de Medicina Veterinária - SUSEME - Secretaria de Saúde - Guanabara - Av. Bartolomeu de Gusmāo, 1120 - GB - Auxiliar de Ensino da Disciplina de Anatomia Patológica e Técnica de Necrópsia da Faculdade de Veterinária de UFF. Recobido para publicação em 23-10-1969. 
Os autores apenas lograram a reprodução da mucormicose cerebral entre os coelhos diabéticos e entre os normais só as lesões nasais. Os resultados obtidos são compreensíveis pelo fato de a mucormicose ser uma complicação do diabete não tratada, e por crescer bem em meios açucarados, o referido cogumelo.

Gleiser, em 1953 (4), descreve a micose em cão da raça Setter Inglês, com lesão renal, um segundo caso em cadela Terrier, com úlcera gástrica, lesão pulmonar, cerebral e cerebelar, um terceiro caso em bezerro, com comprometimento pulmonar.

Baker (1), cita em seu trabalho, a ocorrência de dez casos humanos da micose associada a outras doenças, sendo quatro portadores de diabete, mellitus, dois de leucemia, um de mieloma múltiplo, um de queimadura cutânea, um de diarréia infantil; em um a causa predispoente era desconhecida.

Na literatura médico-veternária brasileira a primeira descrição de um caso de mucormicose, foi feita por Silva e Machado, em 1963 (7), em um bezerro com 3 meses de idade, apresentando nódulos miliares nos pulmões e lesões ulcerativas na língua, tonsilas e reticulo.

Corrêa e Campos () relatam a ocorrência da micose em um cão com 12 anos de idade, o qual mostrava lesão ulcerativas do palato duro e da mandíbula direita.

$\mathrm{Na}$ pesquisa bibliográfica efetuada, não encontramos referência à ocorrência da doença em coelhos, a não ser aqueles casos de cunho experimental. Acreditamos ser a mucormicose espontânea uma doença muito rara no coelho, daí o nosso interêsse em publicar o presente caso.

\section{MATERIAL E MÉTODOS}

O presente caso refere-se a um coelho de raça Chinchila, com aproximadamente 1 ano de idade, com os seguintes dados anamnésiticos: emagrecimento progressivo, inapetência, secreção nasal de aspecto purulento. O animal teve morte espontânea.

À necrópsia encontramos os pulmões com nódulos miliares disseminados. Os demais órgãos não revelavam lesōes dig- nas de nota. Foram coletados fragmentos de diferentes órgãos, os quais fixados em formol a $10 \%$ impregnados em parafina. cortados em micrótomo e corados pela hematoxilina-eosina e PAS, para melhor evidenciação do cogumelo.

No exame histopatológico o pulmāo ap:esentou focos de consolidação constituídos de alvéolos cujas cavidades são ocluídas por células endotelias e por plasmócitos a par de acentuada necrose da

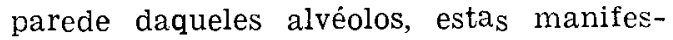
tações de necrose se traduziam por um desaparecimento da estrutura da parede alveolar e presença de abundantes figuras do cariorrexia.

Os focos miliares descritos são freqüentミmente centralizados por vasos cuja luz está ocluída por massa de piócitos, apresentando estas, micélios de cogumelo ramificado e não septado. (Fig. 1 e 2).

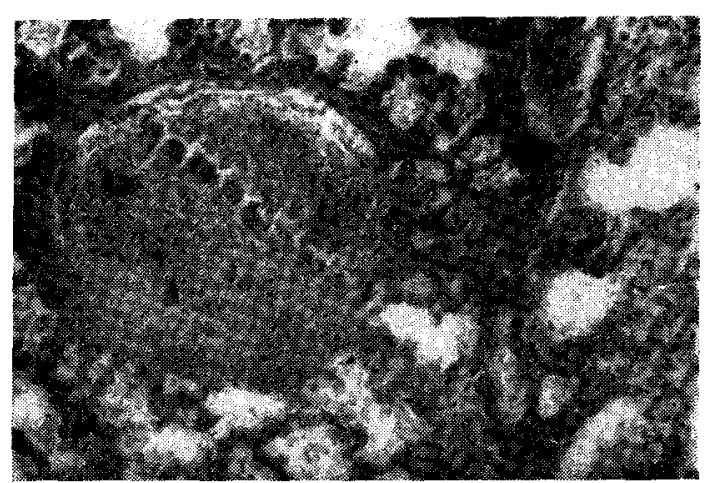

Fig. 1. Pullmào de Coelho -.- H. E. Mostrando um vaso pulmonar ocluido por massas de piócitos.

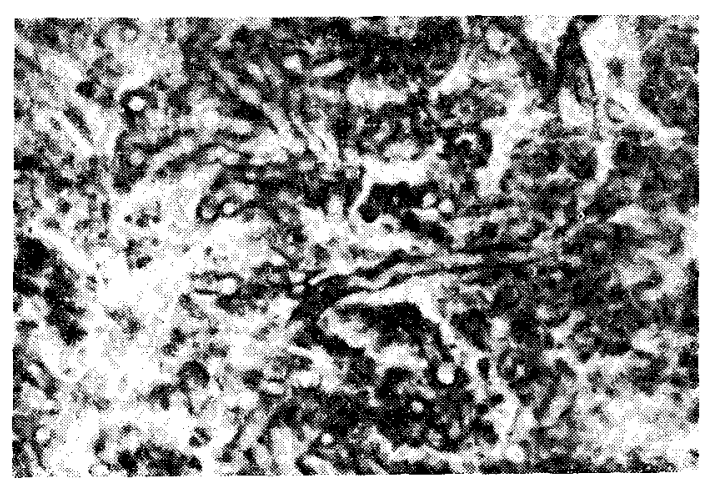

Fig. 2. Pulmáo de Coelho -. P. A. S. Evidenciando $o$ cogumelo ramificado e não septado. 


\section{DISCUSSĀO}

O aspecto morfológico aliado às lesōes determinadas pelo cogumento, tem sido utilizado correntemente como meio de diagnóstico pelos diferentes autores como Paltulf (6), bem como os brasileiros Silva e Machado (7), Correia e Campos (3), que adotaram sempre tal critério.

As lesōes macroscópicas determinadas por êste cogumelo são do tipo ulcerativo ou nódulos miliares. As lesões histopatológicas constantes nesta micose são: necrose, lesōes vasculares com presença de micélios dicotômicos e não septados.

o meio de diagnóstico adotado no presente caso atem-se à morfologia do cogumelo, por näo termos procedido o isola- mento e posterior reprodução experimental da doença. O material examinado apresentou micélios ramificados e não septados, na luz dos vasos pulmonares que centralizavam os nódulos miliares. Convém se acentuar que nesta micose êste critério de diagnóstico é considerado de maior valor do que o isolamento do cogumelo, em virtude da grande ubiquidade dêste.

Os achados, tanto macroscópicos como histopatológicos, coincidem com os registrados na literatura estrangeira e brasileira.

O diagnóstico diferencial com a aspergilose, que é comum entre os animais, é feito pela ausência de septação do Mucor e constante no Aspergillus.

\section{$S U M M A R Y$}

A case of pulmonary mucormycosis in a one year old chinchila rabbit is described. The lungs showed miliar nodules. Using P.A.S. not septed branched myceiia, iocalnzed principally in the small pulmonary vessels, could be ascertained. Around them there was an inflamatory reaction.

\section{B IBLIOGR A FIA}

1. BAKER, R. D. - Pulmonary mucormycosis. Amer. J. Pathol, 32: 287$313,1956$.

2. BAUER, H., FLAMAGEN, J.F., SHELDON, W.H. - Experimental cerebral mucormycosis in rabbits with diabetes. Yale. J. Biol. Med., 28: 29-36, 1956.

3. CORREA, W.M., CAMPOS, J.M. Nota sôbre um caso de mucormicose em cão. Rev. Med. Vet. 2.1: 58-59, 1966.

4. GLEISER, A.C. - Mucormycosis in animal. J. Am. Vet. Med. Ass. 123: 441-445, 1953.
5. MCQUOWN, A.L. MOSS, E.S. - Atlas of Medical Mycology. Williams \& Wilkins. Co. Baltimore, 1953.

6. PALTULF. A. - Mycosis mucorina. Virchows. f. pathol. Anat. 102: 543564. in Silva e Machado (1963), 1885.

7. SILVA, J.M.L., MACHADO, A.V. Mucormicose generalizada em bezerro. Arquivo da Escola de Veterinária. Belo Horizonte. XV, 133-138, 1963.

8. SMITH, T. - Mycosis of the Bovine Fetal Mebranes Due to a Mould of the Genus Mucor. J. Exp. Med. 81115-122, 1920 .

9. ZAPATER, C.R. - Micologia Alergógena. EL ATENEO "Editorial". Buenos Aires, 1953. 


\section{CONFERENCIA INTERNACIONAL de TÉTANO — SÃO PAULO, 1970}

Será realizada em São Paulo, no periodo de 17 a 22 de agôsto de 1970, a III Conferência Internacional de Tétano, sob os auspícios da Organização Mundial de Saúde, Oficina Sanitária Pan-americana e Academia de Medicina de São Paulo. A III Conferência Internacional de Tétano terá como local de reuniōes as magníficas instalaçōes dos Laboratórios Carlo Erba de São Paulo, que conta com perfeitas instalações audio-visuais, serviço de gravação e tradução simultânea, além de perfeito serviço de ar condicionado.

Deverão comparecer, além das delegações oficiais da Organização Mundial de Saúde e Oficina Sanitária Pan-americana, $j a ̉$ designadas, renomados cientistas de cêrca de 15 países. As sessões serão distribuídas pelos seguintes temas: Microbiologia (Prof Nishida, do Japão), Epidem ologia (Dr. Cvjetanovic, OMS), Imunologia (Prof. Edsall, Estados Unidos), Profilaxia (Prof. Eckmann, Suissa), Terapêutica (Prof. Patel, India) e Estandardizações (Dra. Pitmann, Estados Unidos).

As sessões constarão de conferências sôbre os respectivos assuntos, mesas redondas, temas livres e discussões abertas.

A Conferência tem como Presidente de honra o Senhor Governador do Estado e terá interessante programa de atividades sociais programadas pela secretaria de Turismo do Estado e Prefeitura de São Paulo.

o Presidente da II Conferência Internacional de Tétano é o Prof. Ricardo Veronesi - Caixa Postal, 8091, São Paulo. 